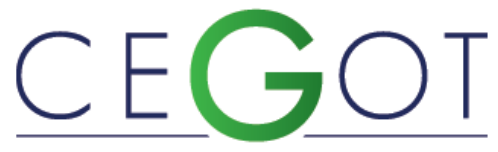

Centro de Estudos de Geografia e Ordenamento do Território

\author{
NASCIMENTO, JOSÉ \\ Universidade Federal do Ceará - UFC, Centro de Ciências \\ Sociais - Programa de Pós-Graduação em Administração e \\ Controladoria (PPAC) \\ Universidade Estadual do Piauí - UESPI \\ 60020-180, Av. da Universidade, 2431 - Benfica, Fortaleza - CE, Brasil \\ jwnascimento01@gmail.com \\ BarRos Neto, José \\ Universidade Federal do Ceará - UFC, Centro de Ciências \\ Sociais - Programa de Pós-Graduação em Administração e \\ Controladoria (PPAC) \\ 60020-180, Av. da Universidade, 2431 - Benfica, Fortaleza - CE, Brasil \\ barrosneto@gercon.ufc.br
}

\title{
O Processo de Planejamento Estratégico Territorial (PET): Análise da Plataforma Ceará 2050
}

\author{
The Territorial Strategic Planning (PET) Process: Analysis of the Ceará 2050 Plataform
}

Referência: Nascimento, José; Barros Neto, José (2020). O Processo de Planejamento Estratégico Territorial (PET): Análise da Plataforma Ceará 2050. Revista de Geografia e Ordenamento do Território (GOT), nㅇ 20 (dezembro). Centro de Estudos de Geografia e Ordenamento do Território, p. 27-56, dx.doi.org/10.17127/got/2020.20.002

\section{RESUMO}

Este trabalho tem como objetivo propor diretrizes para o processo de Planejamento Estratégico Territorial (PET). Foi utilizada uma pesquisa de natureza qualitativa, com objetivos exploratórios e descritivos executada através de um estudo de caso, mediante entrevistas semiestruturadas com 4 coordenadores do projeto Ceará 2050 e 4 membros da equipe do governo cearense. Os dados foram tratados por meio da análise de conteúdo e operacionalizados no software Atlas.ti 8. Como resultados, foram identificadas três etapas do processo de PET: (1) Análise do território; (2) Planejamento territorial e (3) Governança territorial. Propõem-se 4 diretrizes para o PET: 1) O território compreendido como elemento estratégico do planejamento; 2) 0 ordenamento territorial é essencial para 0 desenvolvimento/planejamento; 3) Governança com plena participação social; e 4) Seguir as demais diretrizes, proporciona ao desenvolvimento territorial.

Palavras-chave: Planejamento Estratégico Territorial; Processo; Ordenamento; Plataforma Ceará 2050.

\section{ABSTRACT}

The objective of this work was to propose guidelines for the PET process. Using a qualitative research with exploratory and descriptive objectives, carried out through a case study; through semi-structured interviews with 4 coordinators of the Ceará 2050 project and 4 members of the Ceará government team. Data were processed through content analysis and operationalized in Atlas.ti 8 software. As a result, three PET process steps were 
identified: (1) Territory analysis; (2) territorial planning; and (3) Territorial governance. Four guidelines for PET are proposed: 1) The territory understood as a strategic element of planning; 2) Territorial planning is essential for development / planning; 3) Governance with full social participation; and 4) Following the other guidelines provides territorial development.

Keywords: Strategic Territorial Planning; Process; Ordering; Ceará 2050 platform.

\section{Introdução}

$\mathrm{Na}$ literatura contemporânea sobre a teoria do planejamento deparamo-nos com frequência com os conceitos de planejamento. O planejamento está relacionado ao método científico utilizado na formulação de políticas, por meio de um o esforço consciente para aumentar a validade das políticas no presente e futuro. Ou seja, a validade do planejamento é um atributo do processo pelo qual as decisões são tomadas (El-Kholei, 2016). Isso não significa que os planejadores dominem o campo da política. Todavia, a capacidade de planejar resulta da vontade dos planejadores e da sua conceitualização do território e de outros elementos do "ambiente de decisão". Alguns autores têm colocado ênfase na "cultura de planeamento" (o velho argumento sobre o ideal - normativo - e o possível real - na teoria do planejamento), mas como determinante do "planejamento da conduta", da ação dos decisores (Faragó, 2004; Dasí \& Pastor, 2016).

Nesse sentido, o planejamento não é tarefa somente dos planejadores. Pois, "em síntese, [...] as decisões do que fazer, do futuro desejado, será sempre dos agentes [ou atores] diretos, sendo que as técnicas e os técnicos entram como viabilizadores e animadores do processo de concepção do plano. Politicamente decide-se o que fazer; tecnicamente definese como fazer" (BECKER, 1998:89). Ou seja, "o planejador assume os objetivos (escolhas) a serem dados na situação e é racional com relação apenas aos meios". Nesse caso, o planejador recebe os objetivos, um tomador de decisão, ou - com menos frequência ele os postula. Essa abordagem, geralmente, acompanha um empirismo ingênuo, que requer não apenas a exploração e descrição dos fatos, mas também, pressupõe que esses fatos sejam sistematizados por eles mesmos (de acordo com suas próprias leis).

Assim, o planejamento é um campo interessante. Ou seja, seus acadêmicos e profissionais mantêm uma tradição de questionamento e descontentamento com a capacidade e a 
vontade da profissão de atender aos padrões e níveis de desempenho que eles gostariam, mas o campo ainda progride. Seu caráter reflete as principais tendências da vida política, econômica, social, urbana e rural, mas o planejamento também possui sua própria mistura única de idealismo e profissionalismo que o diferencia de outros grupos no mundo das políticas. Nesse ponto, o campo é desafiado por questões sérias que vão desde debates sobre a natureza do urbano e rural até a aceitabilidade ideológica da intervenção pública e regulamentação do desenvolvimento (Dasí \& Pastor, 2016).

Em resposta a esses desafios desponta o campo do planejamento territorial, bem como os arranjos de governança que lhe são correspondentes. Do ponto de vista do planejamento, o passo de ordenar o território é essencial na medida em que significa reconhecer as vocações produtivas e de conservação dispostas no território, assim como as dinâmicas socioeconômicas e as expectativas da própria sociedade local sobre o espaço e seus recursos. É o que fornece as bases para uma costura inaugural de acordos e para uma visão integrada de futuro cujo potencial seja demonstrável e monitorável.

Um processo de planejamento com as características acima descritas, para a maioria das regiões ou territórios, ainda é um desafio a ser enfrentado. Talvez seja este um dos motivos que levam cidades, municípios, regiões territórios e, até estados e países, como é o caso do Brasil, a mudar suas estratégias de desenvolvimento a cada administração, sem um processo de planejamento marcado pela continuidade.

Nessa lógica, surge a importância de analisar o processo do plano estratégico para territórios. Nesse caso específico, o planejamento estratégico para o estado do Ceará: Projeto Ceará 2050. Este projeto busca um olhar atento à questão das etapas que compõem o Planejamento Estratégico voltado para os territórios; no caso, o território do estado do Ceará. Assim, tem-se como questão de pesquisa: como aprimorar o processo de Planejamento Estratégico Territorial (PET), na Plataforma Ceará 2050? O objetivo geral desta pesquisa foi propor diretrizes para o aprimoramento do processo do PET, na Plataforma Ceará 2050.

Este artigo contempla, inicialmente, algumas reflexões sobre a evolução da teoria do planejamento. Uma segunda temática é o processo de planejamento estratégico territorial. Em terceiro lugar, são discutidas algumas diretrizes e implicações dos princípios defendidos 
na prática do planejamento. A reflexão é centrada na experiência de planejamento estratégico desenvolvido na Plataforma Ceará 2050, estado da região Nordeste do Brasil.

\section{Reflexões sobre Planejamento}

De acordo com a literatura revisada, infere-se que a teoria do planejamento foi uma receita de como organizar a tomada de decisões, um conjunto de postulados gerais não necessariamente confinados a preocupações com "cidade e país", nem vinculados a nenhum estado-nação em particular. Muito do trabalho de base dessa teoria foi realizado nos EUA, por autores como Davidoff e Reiner, Meyerson e Banfield e muitos outros. Nesse sentido, faz-se necessário uma revisão da literatura sobre a teoria do planejamento. Como vê-se a seguir.

\subsection{Planejamento Estratégico nos Estado Unidos}

O desenvolvimento da teoria do planejamento do pós-guerra se baseou em escritos teóricos sobre a natureza do planejamento, mas até a década de 1960 considerações técnicas e práticas dominavam a educação em planejamento. A ideia de "teoria do planejamento" foi desenvolvida na década de 1960 na América do Norte. Na Universidade de Chicago, em particular, havia desenvolvido uma escola muito influente que via o planejamento como um processo geral de tomada de decisão (Teitz, 1996).

Nesse sentido, a teoria do planejamento tem sido um "campo de batalha" nos debates sobre planejamento. Os conflitos sobre a relevância do modelo racional de planejamento eram endêmicos, pois eram desafiados pela ciência social incrementalista, pelo estruturalismo marxista, pela teoria da aprendizagem social, pelas teorias organizacionais do planejamento e por qualquer número de outras importações teóricas que procuravam revelar a verdadeira natureza do planejamento.

Por conseguinte, na década de 1960, o planejamento racional-abrangente era o método mais frequentemente aplicado, o que contribuiu muito para a aceitação geral do planejamento e ainda é recomendado em nossos dias. Seus defensores afirmam que, ao aplicar algum princípio de racionalidade de maneira uniforme, podemos mobilizar o conhecimento atualmente disponível para a solução dos problemas sociais e, assim, nos aproximarmos da consecução de um grande fim geral. 
Até a década de 1970, o planejamento racional-abrangente e o planejamento físico predominavam nas atividades de planejamento dos governos locais e de outros órgãos. A abordagem estratégica apareceu pela primeira vez no planejamento comunitário/espacial na década de 1980. O planejamento estratégico foi introduzido pela primeira vez em alguns estados (por exemplo, Califórnia, Ohio, Wisconsin) e grandes cidades (por exemplo, São Francisco, Filadélfia, Nova York etc.) dos EUA. O Relatório Nacional de Política Urbana publicado em 1982 fala sobre abordagem estratégica, pontos fortes e fracos internos, ameaças e oportunidades externas. Este é um bom exemplo do fato de que o planejamento estratégico foi praticado não apenas na economia, mas também para integrar as abordagens setoriais nos níveis municipal ou estadual (Sorkin, Ferris e Hudak, 1984).

De acordo com a literatura, na década de 1990, surgem as escolas de Mintzberg (1990, 1994), com aspectos específicos que contribuem para a compreensão do todo. Bem como, as abordagens especiais que elas usam. Não obstante, como essas escolas apontaram, o desenvolvimento da estratégia pode ser interpretado simultaneamente como um processo de cognição regulado em grandes detalhes, um processo analítico, a criação de uma visão e uma concepção, um processo de aprendizado, um processo de negociação etc., e não apenas um destes. No caso de aplicações específicas e seus vários estágios, no entanto, pode ser dada prioridade a esse ou outro "método" (Mintzberg, 1994).

Por conseguinte, observa-se, após a década de 1990, que a teoria do planejamento é separada do planejamento prático, tornando-se altamente abstrata e fornecendo cada vez menos links com a prática, resultando no distanciamento da teoria do planejamento da prática de planejamento, o que é bem conhecido na literatura de planejamento como o "lacuna teoria-prática" (Alexander, 1997, 2016; Breheny, 1983; Harrison, 2014; Muller, 1992; Pissourios, 2013; Watson, 2008). Essa alteração coincide com a mudança paradigmática da teoria do planejamento em direção ao pós-modernismo (Taylor, 1998; Allmendinger, 2002; Lagopoulos, 2018a). Nesse contexto, tornou-se comum entre os acadêmicos caracterizar o planejamento como "moderno" ou pelo menos como parte do projeto de modernidade. 


\subsection{Planejamento Estratégico na Europa}

O surgimento do conceito de "teoria do planejamento" na Europa, ilustra sua estreita associação com a legitimação do planejamento americano (Hague, 1991). A forma de teoria do planejamento que veio à tona foi a que buscava abordar problemas burocráticos de tomada de decisão, além de estabelecer uma área clara, porém flexível, de preocupação especial, a saber, o processo de escolha racional com uma orientação futura no setor público. Assim, Reade (1987), ao revisar o Planejamento, classificou o período desde 1960 como: "O triunfo do profissionalismo burocrático".

Assim, no final da década de 1970, a teoria do planejamento era dominada por duas principais opções: teoria processual e uma crítica marxista do planejamento como ação e ideologia do Estado. Tudo isso é história, altamente generalizada, mas amplamente inconteste, desde que se reconheça que nem todo planejador era um teórico processual na década de 1960 e um marxista na década de 1970. A tradição marxista era sem dúvida mais firmemente plantada na Europa continental. Ou seja, o argumento é que características históricas específicas do estado e as práticas de planejamento podem ser identificadas para explicar quais ideias floresceram e quais murcharam. A teoria do planejamento na Europa tem sido principalmente um exercício de construção (ou demolição) da legitimação do planejamento.

No início dos anos 80, a teoria do planejamento estava se fragmentando. Os anos 80 viram o descrédito do modelo de planejamento central que operava na União Soviética e em seus satélites. A ideologia do livre mercado da década de 1980 seguiu seu curso, e a nova moda foi a de mecanismos que operam em uma estrutura de mercado, mas com uma medida mais forte de responsabilidade pública. O tipo de controle regulatório limitado das operações de mercado que tipificou o planejamento a adquirir uma nova relevância. $\mathrm{Na}$ medida em que a teoria do planejamento na Europa está entrelaçada com a legitimação do planejamento (positiva ou negativamente), a necessidade nos anos 90 é desenvolver a teoria para uma forma de planejamento participativo, regionalista, reguladora e redistributiva.

Essa forma de planejar é difundida por Borja e Castells a partir do sucesso de Barcelona, com a derrocada das formas tradicionais de planejamento. O modelo defendia que as 
políticas públicas urbanas - por meio da parceria público-privada - teriam a capacidade de resolver os problemas urbanos e tirar as cidades da crise. Isso só acontece em virtude da crise do modelo fordista e do estado keynesiano, bem como a consequente queda do administrativíssimo, que deu lugar ao empresariamento urbano.

Por seu turno, outros teóricos contemporâneos do planejamento europeu, destacam-se os franceses: Jacques Lévy (2003), Carrière (2004), Guesnier, Carrière \& Bock (2004), Mathis (2004) entre outros. Estes fazem reflexões relevantes sobre o planejamento europeu, em especial na França. Destacando uma abordagem policial multi-escalar, para o desenvolvimento territorial, por meio da observância das diversidade e estratégias adequadas para cada território. Proporcionando a observância do ordenamento territorial e as consequências nos territórios de planejamento.

Por conseguinte, atualmente, a questão do planejamento nos países membros da União Europeia caracteriza-se por um tenso jogo de lideranças, captação e gestão de recursos financeiros. Múltiplos atores e instituições intermediam a formação de redes e parcerias, tendo em vista a dotação de fundos e recursos estruturais destinados aos âmbitos regional e urbano (Conti, 2007). O Conselho Europeu desempenha um relevante papel gestor desse processo, ao definir políticas territoriais que tenham nas cidades e em suas relações sinérgicas o principal tema e como exigência o estabelecimento de redes cooperativas de cidades, fundamentadas na ação intergovernamental (Abascal \& Bilbao, 2018).

\subsection{Planejamento Estratégico na América Latina}

Na América Latina, o planejamento, destaca-se a partir da década de 1960. Nesse período, o modelo normativo desenvolvimentista de planejamento foi eleito pela Comissão Econômica para a América Latina e o Caribe (Cepal) como o mais adequado para a superação dos problemas latino-americanos. Ainda hoje, os planejamentos governamentais no Brasil ou na América Latina são predominantemente normativos (Costa Filho, 2010:14).

Nessa linha, Matus (1984) e outros autores utilizam o termo planejamento para se referir ao modelo de planejamento estratégico, desenvolvido no âmbito da Cepal, a partir da segunda metade do século XX. Os autores dessa tradição, de maneira geral, acreditavam que seria possível alcançar o interesse geral mediante o uso de instrumentos e técnicas de planejamento e assim este seria aceito pela maioria das pessoas de boa vontade. Nessa 
perspectiva, os autores acreditavam que o consenso poderia ser planejado (Friedmann, 1987:136).

Assim, na América Latina, o planejamento tradicional tem como uma de suas características a hegemonia da dimensão econômica, evidenciada no entendimento do planejamento como uma técnica que visa à racionalização e à otimização da aplicação de recursos, definindo seus objetivos e meios para alcançá-lo em função do custo/benefício econômico. Nesse sentido, considera-se o aspecto político como um dado exógeno, entendendo que a realidade apresenta comportamentos sociais estáveis e previsíveis, passíveis de serem estudados por meio de modelos analíticos. Onde as metas são estabelecidas buscando-se uma situação de máxima racionalidade. E, o diagnóstico é feito a partir da análise do comportamento histórico, orientando-se, no entendimento dos planejadores, pela busca da verdade objetiva e científica.

Já na visão de futuro, o objeto do estudo é considerado estático e passivo, partindo-se do pressuposto de que o planejador tem todos os poderes e o objeto tende a se submeter às mudanças planejadas, e na análise da trajetória consideram-se os cenários tendenciais e normativos e admitindo-se trajetória única. O planejamento tradicional, segundo a literatura, seria vocacionado às instituições em que exista uma considerável concentração de poder e, portanto, não haja heterogeneidade de forças em disputa, além de um razoável consenso social (Giovanella, 1991; Rivera, 1992).

Não obstante, teóricos europeus, também influenciaram o pensamento do planejamento latino. Autores como Jordi Borja e Manuel Castells estão entre os pioneiros na sistematização teórica do planejamento estratégico na América Latina (Silva, 2012). Os autores citados foram responsáveis, através do estabelecimento de consultoria internacional, pela difusão mundial desse modelo de planejamento - no caso, o modelo catalão, em particular na América Latina. Esse novo paradigma, o chamado "Planejamento Estratégico de Cidades", foi difundido pelo mundo a partir do "sucesso de Barcelona" (Castells \& Borja, 1996, p. 155).

Por fim, na América Latina, ainda hoje, os planejamentos governamentais, principalmente no Brasil são predominantemente normativos (Costa Filho, 2010:14). Nesse sentido, o planejamento é, então, introduzido na América Latina enquanto método de seleção de 
alternativas que otimiza a relação entre objetivos e instrumentos com o propósito de crescimento, pois dentro das teorias desenvolvimentistas, entende-se ser o crescimento a solução para o subdesenvolvimento.

\subsection{Planejamento Estratégico no Brasil}

De acordo com a literatura revisada, no Brasil, quando o assunto é planejamento, especialmente planejamento estratégico, a reação, em geral, é de apatia, de indiferença. Observações, entre outras, como as apresentadas a seguir são bastante comuns (Giacobbo, 1997):

\footnotetext{
“Para que planejar? O brasileiro é diferente: ele tem jogo de cintura; ele sabe improvisar, na hora $\mathrm{H}$ ele sempre dá um jeitinho.

No Brasil, planejamento não pega. Aqui tudo é diferente, a começar do Governo que sempre muda tudo de uma hora para outra.

Se você não sabe para aonde vai (destino), todos os caminhos o levam para lá.

Não adianta tentar prever o que vai acontecer porque a realidade será sempre diferente."
}

Nessa perspectiva, primeiras experiências de planejamento estratégico no Brasil começam no início da década de 1950 com a preparação dos primeiros planos diretores de Porto Alegre e São Paulo. Os planos diretores começam a ser implantados em larga escala durante a ditadura militar, na década de 1970, num ambiente exclusivamente urbano das grandes cidades brasileiras (Brasil, 2001; Krambeck, 2007; Graziano, 2007).

Nesse contexto, em meados da década de 1990, algumas cidades contrataram empresas de consultoria para realizar tais planos. Assim, destaca-se a experiência do Rio de Janeiro, por ser uma das primeiras a estar entre essas cidades a elaborarem seu plano (Silva, 2012). Plano este, que seguia o "Planejamento Estratégico de Cidades", amplamente difundido a partir do "sucesso de Barcelona", que tinha como criadores os teóricos espanhóis Manuel Castells e Jordi Borja. Embora bastante difundido, o modelo encontrou mais tarde os seus críticos, como revela o trecho a seguir:

Não faltam aqueles que oferecem, a preços não módicos, fórmulas capazes de conduzir qualquer cidade ao pódio restrito das cidades globais. Os clientes, muitos prefeitos latino-americanos, buscavam salvar suas municipalidades da insolvência promovida pela crise fiscal, seguindo o modelo mais vendido do continente: Planejamento Estratégico, à la Barcelona (Maricato, 2001, p. 57). 
Esse modelo, que ia se difundindo pelo mundo, defendia que "o governo local capaz de dar resposta aos atuais desafios urbanos e de construir um projeto de cidade, assim como de liderá-lo, tem de ser um governo promotor" (Castells \& Borja, 1996, p. 158). É o governo local que, para sair da crise, precisa agir como um ator privado, de modo a se promover no cenário competitivo no qual deve se enquadrar.

Não obstante, no contexto dos estados brasileiros, o planejamento estadual caracteriza-se, em geral, pela falta de visão estratégica a longo prazo (Brasil, 2001; Graziano, 2007; Ceará, 2017). Ou seja, uma consequência dessa cultura do curto prazo, no contexto cearense, é a inexistência de uma visão estratégica do Estado numa perspectiva de 20 ou 30 anos à frente, que oriente as formulações de políticas públicas de curto e médio prazos (Brasil, 2001; Ceará, 2017, 2018). Nesse sentido, precisa-se compreender o processo de planejamento estratégico territorial, como vê-se a seguir.

\section{Planejamento Estratégico Territorial}

O Planejamento Estratégico Territorial (PET) é uma ferramenta de gestão para enfrentar as mudanças nas áreas urbanas e rurais de maneira consensual, com base na participação dos principais atores locais - governos, academia, setor privado e a sociedade (Ruano, 2019). Os primeiros planos estratégicos aplicados em territórios surgem em cidades norte-americanas no início do século XX. Estes visavam aliviar os efeitos da crise econômica da década anterior por meio de iniciativas de incentivar o crescimento e desenvolvimento econômico (Ruano, 2019).

O PET supõe uma definição consciente da orientação e da destinação de seus recursos e ativos existentes (recursos naturais, atividade industrial, capital humano etc.) e das modalidades de exploração dos seus recursos e ativos potenciais do território (Reese, 1999; Gutiérrez, 2014; Zhikharevich \& Pribyshin, 2014).

Zhikharevich e Pribyshin (2014) definem o PET "como a determinação independente de objetivos, com a direção principal do desenvolvimento socioeconômico sustentável em um ambiente competitivo dinâmico". Devendo ajudar a especificar a direção do desenvolvimento territorial. Corroborando com os autores, Viktorovna (2014) destaca que 
“o desenvolvimento territorial é o elemento mais importante no sistema de gestão estratégica".

Já para Cirio (2016) planejar o desenvolvimento territorial, requer a adoção de diversas variantes que perpassam com nuances "os paradigmas situacionais e estratégicos" dos processos do PET. Para o autor, os paradigmas assumem que o planejamento é um processo conduzido por diretrizes metodológicas.

Nesse contexto, Aliseda e Velarde (2018a) destacam que essas diretrizes, desenvolvem-se em ciclos de três fases: análise do território, planejamento territorial e gestão territorial. Estes compõem os processos do PET, envolvendo aspectos técnicos e metodológicos, sendo um processo contínuo e sistemático, que diz respeito à definição de uma visão de futuro, à formulação de diretrizes estratégicas e à elaboração de projetos que viabilizem e sustentem o caminho traçado, levando em conta as condições internas e externas à região e sua evolução esperada (Dallabrida, 2015; Rio Grande Do Sul, 2016; Azevedo \& Bardal, 2016; Viana, 2018; Silveira \& Pereira, 2018; Aliseda et al., 2018b), conforme vê-se na Figura 1.

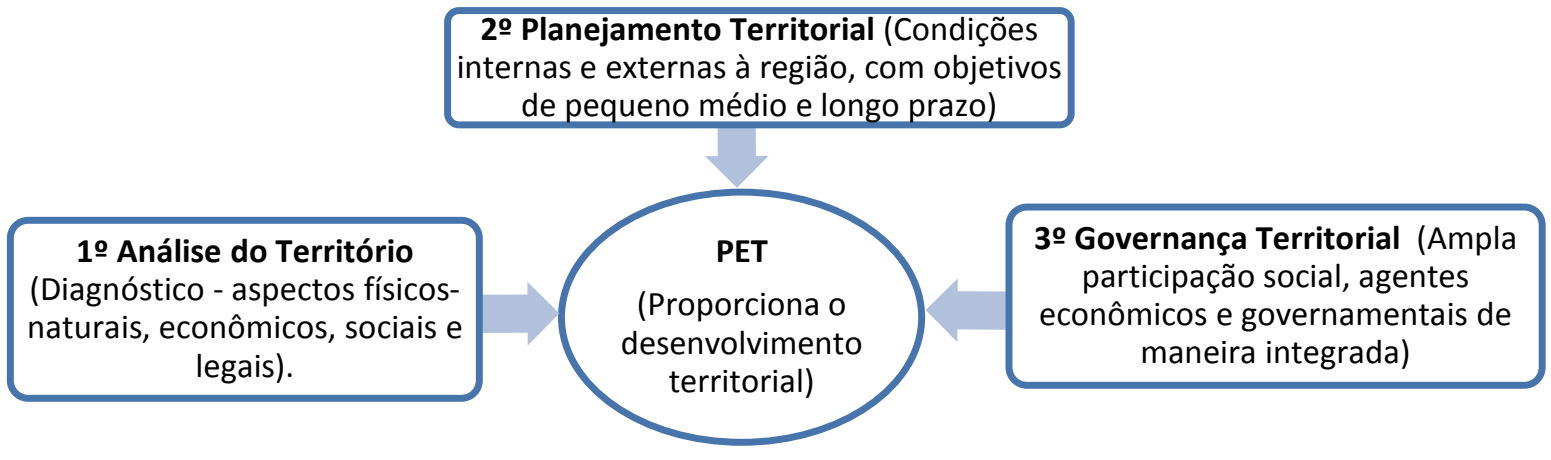

Figura 1 - Processo do PET

Fonte: Dos autores a partir de Zhikharevich \& Pribyshin (2014); Viktorovna (2014); Escudero (2014); Viana (2018); Silveira; Pereira (2018); Aliseda; Velarde (2018a, 2018b).

Depois do exposto e dialogando com todos os autores citados, pode-se ressaltar o processo do PET, envolve aspectos técnicos e metodológicos - (análise do território, planejamento territorial, e gestão territorial). Este deve ser composto por objetivos de pequeno, médio e longo prazo; deve conceber um diálogo social e de tomada de decisão, com todos os atores sociais, agentes econômicos e governamentais, de forma que essa estrutura de gestão com participação social, onde todos pensem de forma integrada para se alcançar o 
desenvolvimento territorial (Zhikharevich \& Pribyshin, 2014; Viktorovna, 2014; Escudero, 2014; Dallabrida, 2015; Rio Grande Do Sul, 2016; Azevedo \& Bardal, 2016; Viana, 2018; Silveira \& Pereira, 2018; Aliseda \& Velarde (2018a).

\section{Método de Pesquisa}

A presente pesquisa foi desenvolvida por meio de um estudo de caso de natureza qualitativa com objetivos exploratórios e descritivos (Babbie, 1998; Collis \& Hussey, 2005; Yin, 2010). Além disso, buscou-se avaliar e descrever as características do fenômeno estudado (Collis \& Hussey, 2005), ou seja, buscando extrair os significados múltiplos de um fenômeno (Richardson, 2017), formando o conhecimento a partir do fenômeno estudado e propondo generalizações analíticas.

Foram coletados documentos (Cellard, 2010) na forma de planilhas de indicadores e relatórios de análise, de modo a complementar as entrevistas, conforme a caracterização apresentada como: D001: Termo de Referência do Projeto Ceará 2050; D002: TR do Diagnostico; D003: TR do Produto 4.1 Ceara 2050; D004: Espírito Santo 2025; D005: Espírito Santo 2030; D006: Santa Catarina 2030; D007: Pernambuco 2035: D008: Campina Grande 2035: D009: Fortaleza 2040; D010: Austrália 2030 e D011: Medellín 1968 - 2018.

Elaborou-se um roteiro de entrevista semiestruturada composta por 13 perguntas subdivididas em 4 blocos. Os sujeitos da pesquisa foi composto por 8 (oito) entrevistados. Estes dividem-se em 4 (quatro) coordenadores do projeto Ceará 2050 e 4 (quatro) membros que compõem a equipe do governo e que são responsáveis por acompanhar as etapas de cada produto proposta no Termo de Referência do Projeto Ceará 2050. As entrevistas foram realizadas no mês de maio de 2019, com duração média de 38 minutos cada, o que resultou no total de 5 horas, 4 minutos e 21 segundos. Assim, os entrevistados são apresentados por $E 1, E 2, E 3, E 4, E 5, E 6, E 7$ e E8.

Para analisar os dados, utilizou-se a técnica de análise de conteúdo, que consiste, segundo Chizzotti (2011, p. 115), em um "conjunto de procedimentos e técnicas de extrair o sentido de um texto por meio das unidades elementares". Para tal, realizou-se as seguintes etapas 
(Bardin, 2016): a) pré-análise; b) exploração do material; e c) tratamento dos resultados, inferência e interpretação. Tal análise foi realizada com o auxílio do software Atlas.ti 8.

\section{Resultados e Discussões}

\subsection{Processo do PET no CEARÁ 2050}

Pode-se aferir que o Projeto Ceará 2050 é produto de muitos estudos e reflexões. Este é uma "plataforma colaborativa de planejamento estratégico de longo prazo desenvolvida a partir do diálogo, da liberdade de opinião e da responsabilidade pública" (PLATAFORMA CEARÁ 2050, 2019). Composta pelas seguintes etapas: 1) Diagnóstico; 2) Análise externa e construção de cenários; 3) Elaboração da visão de futuro e objetivos estratégicos; 4) Concepção de projetos estratégicos; e 5) Consolidação dos resultados e dos projetos - apresentação dos resultados das etapas percorridas (ver Nascimento, 2019; Nascimento; Barros Neto, 2019). Diante dessa exposição, cada etapa da Plataforma Ceará 2050, encaixa-se no processo do PET, como vê-se na Figura 2.

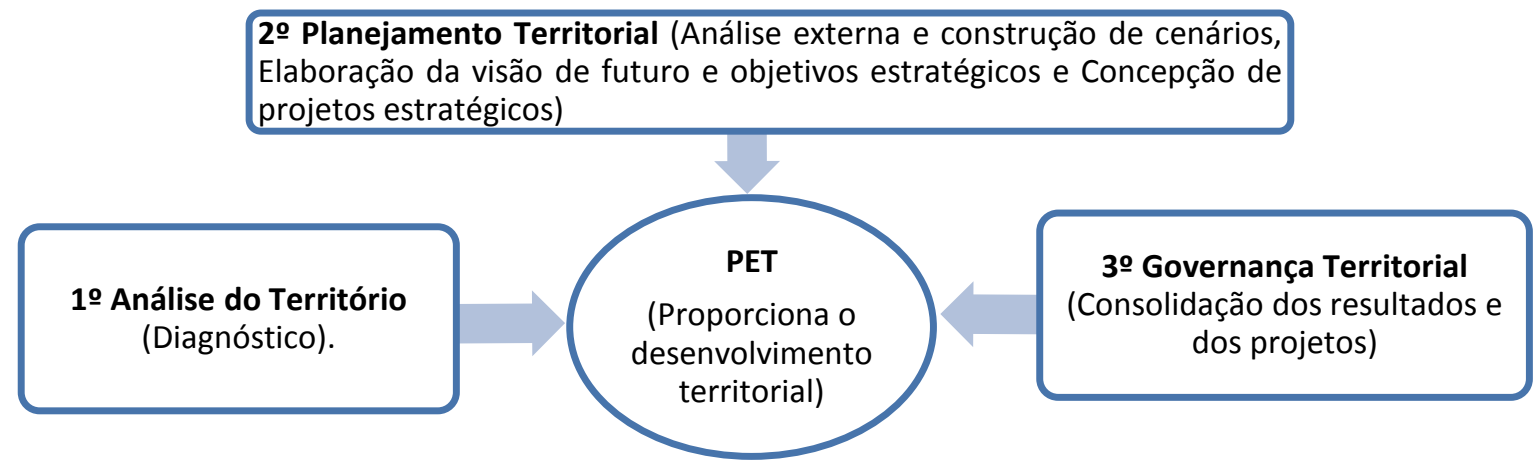

Figura 2 - Etapas da Plataforma Ceará 2050 dentro do Processo do PET

Fonte: Elaborado pelos autores (2019)

Diante do exposto, infere-se que o processo do Projeto Ceará 2050, contempla todas as etapas, quando comparado aos outros planos estratégicos. Entretanto, recomenda-se que a Plataforma Ceará 2050, busque evitar: o planejamento irreal para o território estudado; a escassez de informações na composição dos diagnósticos; a falta de comprometimento da equipe executora; inexistência de métricas para os objetivos estratégicos; negligência ao 
acompanhamento do que foi definido na fase de planejamento e execução; e demora nas tomadas de decisão para executar o que foi planejado.

\subsection{Análises e discussões das entrevistas}

\subsubsection{Etapas do Processo do PET}

Para uma maior profundidade da análise, os resultados são indicados para as unidades de contexto: análise do território, planejamento territorial, governança territorial (Figura 3). Onde todos pensem de forma integrada para se alcançar o desenvolvimento territorial (Zhikharevich \& Pribyshin, 2014; Viktorovna, 2014; Dallabrida, 2015; Rio Grande Do Sul, 2016; Azevedo \& Bardal, 2016; Viana, 2018; Silveira \& Pereira, 2018; Aliseda \& Velarde, 2018a, 2018b).

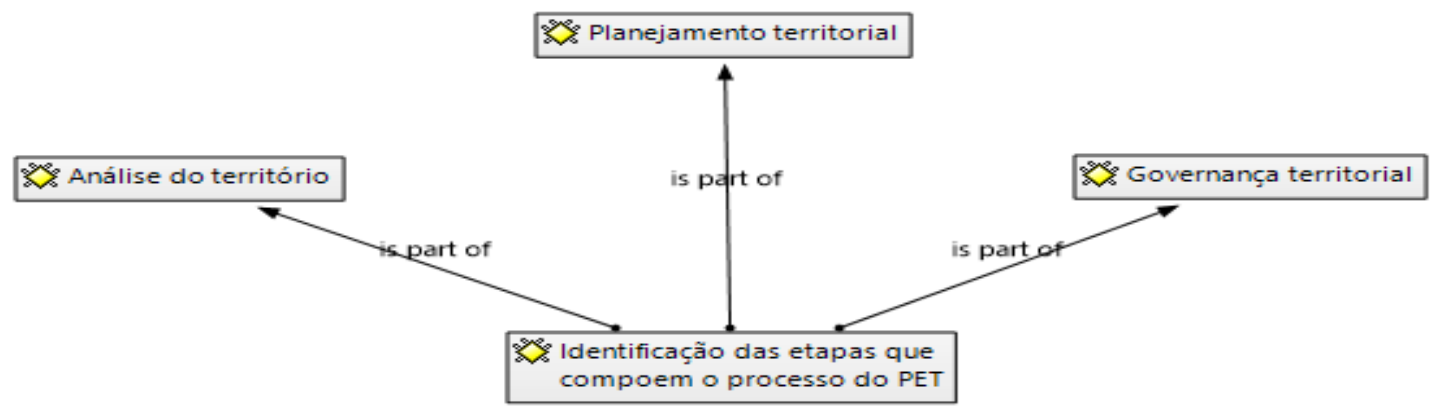

Figura 3 - Etapas do Processo do PET Fonte: Elaborado pelos autores (2019)

Esta figura reflete-se sobre as etapas que compõem o PET. Desta forma, nas subseções seguintes, os entrevistados são questionados sobre as etapas do PET: Análise do território (diagnóstico); Planejamento territorial e Governança territorial.

\subsubsection{Primeira etapa do processo do PET: Análise do território}

A concepção da Plataforma Ceará 2050 buscou sistematizar um diagnóstico com os avanços já observados em gestões anteriores, utilizando-os como insumos para se alcançar o objetivo central de fomentar o desenvolvimento inclusivo e sustentável do Estado (TR Ceará 2050, 2017). Assim, nesse contexto, estudos anteriores como o de Dallabrida (2015) afirma que a análise territorial é concebida como um processo que envolve um recorte territorial 
particular, visando diagnosticar o passado e estabelecer recomendações para o futuro". Este argumento é forçado por E1. Onde o entrevistado reforça que o "o diagnóstico no âmbito dos estados, é fundamental para sabermos os erros do passado." (E1)

E2 e E4, por sua vez, destacam que a análise do território é importante para cada região do estado. Por isso, é necessário mapear, extrair e identificar qual o cenário e o contexto que está inserido a realidade de cada região. Já para E3, o papel do processo de análise territorial é o processo de planejar. Assim, é preciso compreender o passado até os dias atuais. Por conseguinte, percebe-se esse argumento nas falas de E5 e E7, para os entrevistados a análise do território é uma forma de compreender todas as direções que o estado do Ceará tomou nos últimos 30 anos.

Entretanto, verifica-se que E6, destaca que a análise territorial deve ser feita por intermédio de um conjunto de propostas que se faz a partir do entendimento, da interpretação do que se fez aspectos sociais, econômicos, ambientais e territoriais.

Por seu turno, para E8, a análise territorial é, como foi feita na Plataforma Ceará 2050. O entrevistado, cita que nessa etapa, foi feito o diagnóstico do estado nos últimos 30 anos. Em resumo, os entrevistados relacionam a análise territorial, com um diagnóstico que olhe para o passado, reflita sobre o presente e planeje o futuro. Observando as fragilidades, potencialidades e vocações de cada região do planejamento.

\subsubsection{Segunda etapa do processo do PET: Planejamento territorial}

O planejamento territorial deve ser acompanhado para que tudo que foi planejado (método, processos e cronograma) não fujam à normalidade (Zhikharevich \& Pribyshin, 2014; Viktorovna, 2014; Dallabrida, 2015). Para os entrevistados, esse processo percebido de várias formas: o entrevistado E1, destaca que "nessa etapa é fundamental a existência do estado, no sentido de garantir qualidade de vida e a melhoria das condições de vida da população". No entanto, para E2, o planejamento territorial é "uma dinâmica muito importante, porque as regiões, elas funcionam como se fossem um aglomerado de municípios que têm relações sociais, relações econômicas, dinâmicas de comércio, dinâmicas de mobilidade entre as pessoas naquele contexto regional".

Por sua vez, E3 corrobora com a fala de E2. Aquele cita que dentro do planejamento territorial, "você tem que olhar pra economia, é importante que você olhe pra essa 
economia. E isso também varia muito de território para território". Por seu turno, E4, afirma que "está relacionada com o próprio planejamento. O que você tratou na formulação do plano". E5, assim como E4, cita que o planejamento territorial "deve ter objetivos claros, deve ter objetivos gerais bem definidos, objetivos específicos muitos claros". Por fim, E7 ressalta que no planejamento territorial, "temos que criar uma estrutura de governança. Que não é a estrutura de governança do território". A governança do território é realizada pelas autoridades que tem a obrigação e o tem os direitos relativo aquela governança.

\subsubsection{Terceira etapa do processo do PET: Governança territorial}

Por seu turno, em observância a etapa governança territorial, nota-se que esta contempla mais comentários por parte dos entrevistados. Assim, infere-se que a governança territorial tem se tornado um instrumento em que se encontram depositadas as esperanças de uma gestão e de um governo mais efetivo sobre as políticas de desenvolvimento territorial (Abdala \& Nunes, 2018). Entretanto, percebe-se na fala de E1, que esse "instrumento de gestão, apresenta o gargalo de ter um núcleo técnico decisório, e que este núcleo, tenha um lastro político forte". Na visão do entrevistado, esse é o "maior desafio da governança territorial".

Nesse contexto, conforme destaca Gomes (2018), é preciso buscar novas soluções, novos modelos, recortes territoriais consórcios e pactos sociais. Esse apontamento é coerente com a fala de E2, onde o entrevistado destaca, que é importante ter uma espécie de consórcio. Mas, seria uma espécie de pactuação de compromissos entre os atores municipais, estaduais e federais (E2). Assim, segundo a literatura revisada, o processo do PET demanda uma estrutura de governança que organize o contínuo planejamento e repactuação, com participação social, conexão com políticas públicas, monitoramento e informação ampla e objetiva para a tomada de decisão (Azevedo \& Bardal, 2016; Viana, 2018).

Corroborando com o exposto, E3 e E5, comentam que a estrutura de gestão deve ser aberta, flexível, transparente e que permita a participação, representação e articulação entre os atores do governo, academia, setor privado e demais membros da sociedade. Para tanto, é necessário um aparato de governança territorial inclusiva e com representação social, que permita o estabelecimento de prioridades constituídas no próprio território e com clara perspectiva de efetividade (Azevedo \& Bardal, 2016; Viana, 2018). 
Doravante, conforme percebe-se nos depoimentos de E4 e E7, "[a governança territorial] tem que ter realmente pelo menos uma representação dos governos e participação da sociedade". "No caso do governo: o executivo, o legislativo, o judiciário, as representações dos trabalhadores, da universidade, dos empresários, dos vários segmentos eles tem de estar ali de certa forma representados para que você conseguir fazer essa gestão adequada", continua (E4). (E7) concorda com (E4), e acrescenta: "além disso "é você ter núcleos regionais, representativos e participativos com todos os atores envolvidos".

Assim, essa estrutura formal de gestão com participação social, é necessária que tenha conexão com políticas públicas e processos de monitoramento, com informação ampla e objetiva para a tomada de decisão, priorizando as especificidades de cada território (região) (Zhikharevich e Pribyshin, 2014; Viktorovna, 2014; Dallabrida, 2015; Rio Grande Do Sul, 2016; Azevedo \& Bardal, 2016; Viana, 2018; Silveira \& Pereira, 2018; Aliseda \& Velarde, 2018a). Nesse sentido, E6 destaca, que "na governança territorial, você pode ter o monitoramento dos processos de tomada de decisão ocorrendo de forma simultânea." Já para E8, "essa estrutura é onde nós vamos estabelecer mecanismos de participação social. E essa participação será através de fóruns e debates e ao mesmo tempo receber sugestões para a tomada de decisão."

\subsection{Diretrizes para o PET}

De acordo com a literatura revisada, propõe-se 4 diretrizes para o PET: 1) O território deve ser compreendido como elemento estratégico do planejamento, subsidiando a tomada de decisão; 2) O ordenamento territorial é essencial para o desenvolvimento e para o planejamento adequado, nos territórios impactados; 3) Estabelecer governança com plena participação social é imprescindível aos processos de planejamento e 4) Seguir as demais diretrizes, proporciona ao desenvolvimento territorial, conforme vê-se na Figura 4. 


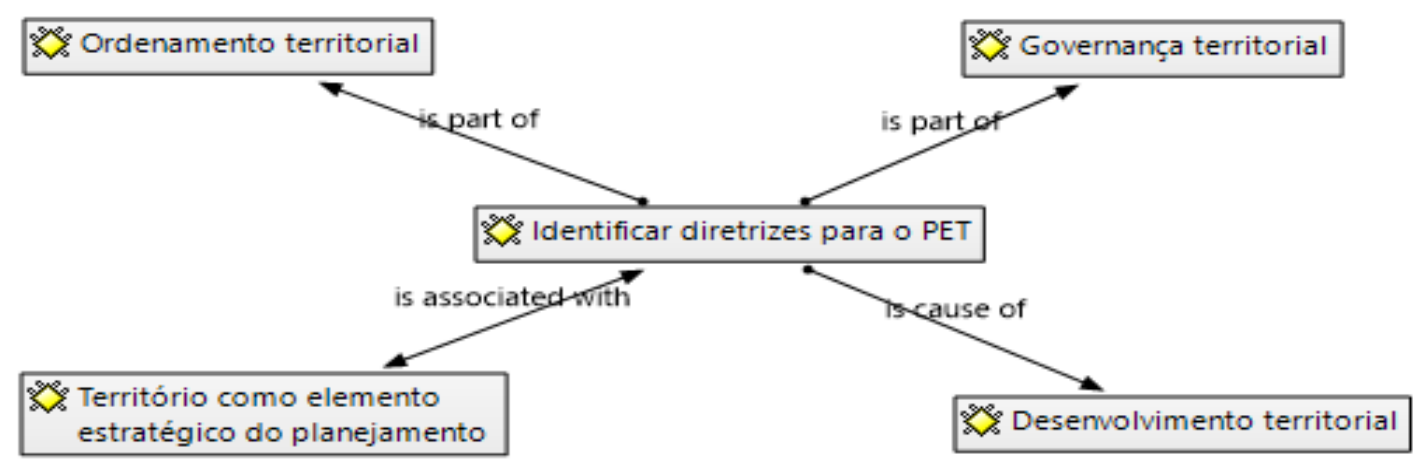

Figura 4 - Diretrizes para o PET no Projeto Ceará 2050

Fonte: Elaborado pelos autores (2019)

Aqui, interprete-se as diretrizes propostas para o PET. Assim, cada entrevistado foi convidado a comentar sobre cada uma. Nessa lógica, nas subseções que seguem, disserta-se mais sobre a função de cada uma dentro do PET.

\subsubsection{Território como elemento estratégico do planejamento}

Nas análises das entrevistas, identificou-se onze trechos que relacionam-se a essa diretriz proposta, exposta na Figura 5.

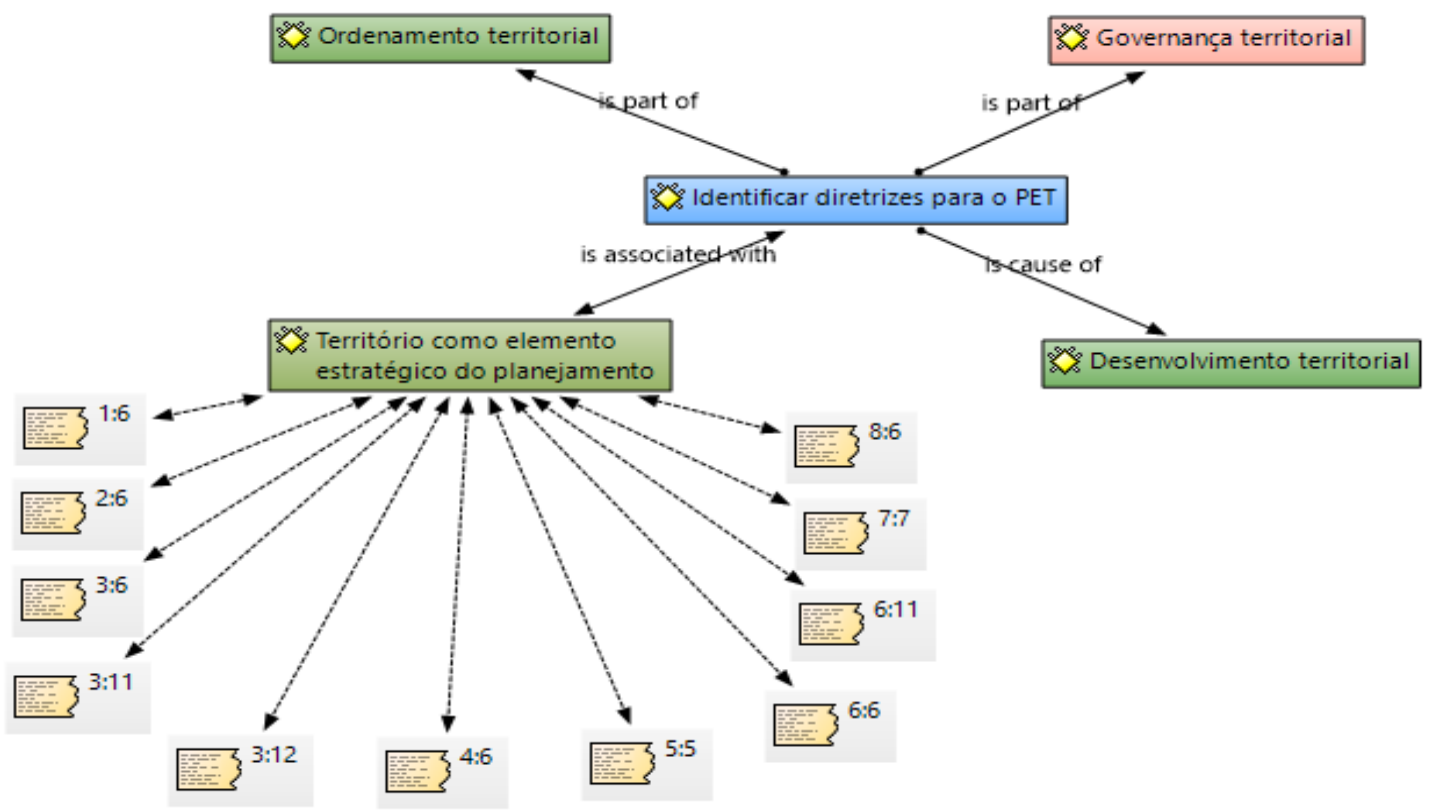

Figura 5 - Território como elemento estratégico do Planejamento Fonte: Elaborado pelos autores (2019) 
Por conseguinte, destacam-se achados da literatura, comparados aos trechos citados pelos entrevistados. Assim, é necessário compreender o território como um elemento estratégico do planejamento, de forma a subsidiar o processo decisório e/ou tomada de decisão (Pinto, Monzoni Neto e Ang, 2018). Corroborando com essa afirmação, observa-se o comentário de E1, ao ser questionado sobre essa temática, destaca que "o território ele assume um papel fundamental". Quer dizer, o território ele pode ser visto como um espaço de tomada de decisão e onde ocorre as relações sociais (E1). Nessa lógica, o Estado busca aperfeiçoar a sua capacidade de planejamento com base na dimensão territorial, aprimorando a participação social, sistematizando e analisando as informações, que garantam processos decisórios, levando em consideração as especificidades de cada território (Pinto et al., 2018).

Corroborando com esse argumento, E2 destaca "o território como elemento estratégico, pois ele possui uma dinâmica que deve ser levada em consideração na hora da tomada de decisão." Por quê? Porque de acordo com o entrevistado, existem diferentes dinâmicas entre as regiões de planejamento" (E2). Pode-se fundamentar o exposto, citando o comentário de E3, "pensar o território de forma estratégica, é pensar nas peculiaridades do estado do Ceará". Diante disso, o entrevistado cita que é necessário distribuir melhor essas oportunidades pelo território, é grande, grande desafio do desenvolvimento territorial (E3).

Por conseguinte, observa-se que E4, concorda com E3. Aquele cita que "quando se considera um território como o estado do Ceará. É necessário considerar algumas particularidades de determinadas regiões." Parafraseando com E4, pode-se assimilar sua fala com o que foi exposto por E5 e E7. Para estes, "o território tem as suas necessidades próprias." Ou seja, a análise estratégica do território, ela consegue, ver as vocações e prioridades pra serem atendidas e muitas vezes, utilizam corretamente as suas vocações e as peculiaridades locais. Por seu turno, E8 discorda dos argumentos dos demais e cita que “o território como elemento estratégico, é discutir, é dissecar o território, dissecar a população, dissecar os seus recursos, dissecar tudo." (E8)

Por fim, observa-se que o território como elemento estratégico do planejamento territorial proporciona: (i) a recomendação de políticas públicas adequadas às demandas locais, por meio da identificação das vocações e peculiaridades regionais; (ii) é possível definir o espaço como plataforma de integração das políticas regionais e locais; (iii) promove a articulação 
entre os entes federativos; e (iv) promove a constituição de ambientes favoráveis a cooperação e a inserção de atores políticos, necessários e legítimos. Favorecendo à constituição de planos efetivos de desenvolvimento territorial.

\subsubsection{Ordenamento territorial}

Nas análises das entrevistas, identificou-se nove trechos que relacionam-se a essa diretriz proposta. Conforme expõe-se na Figura 6.

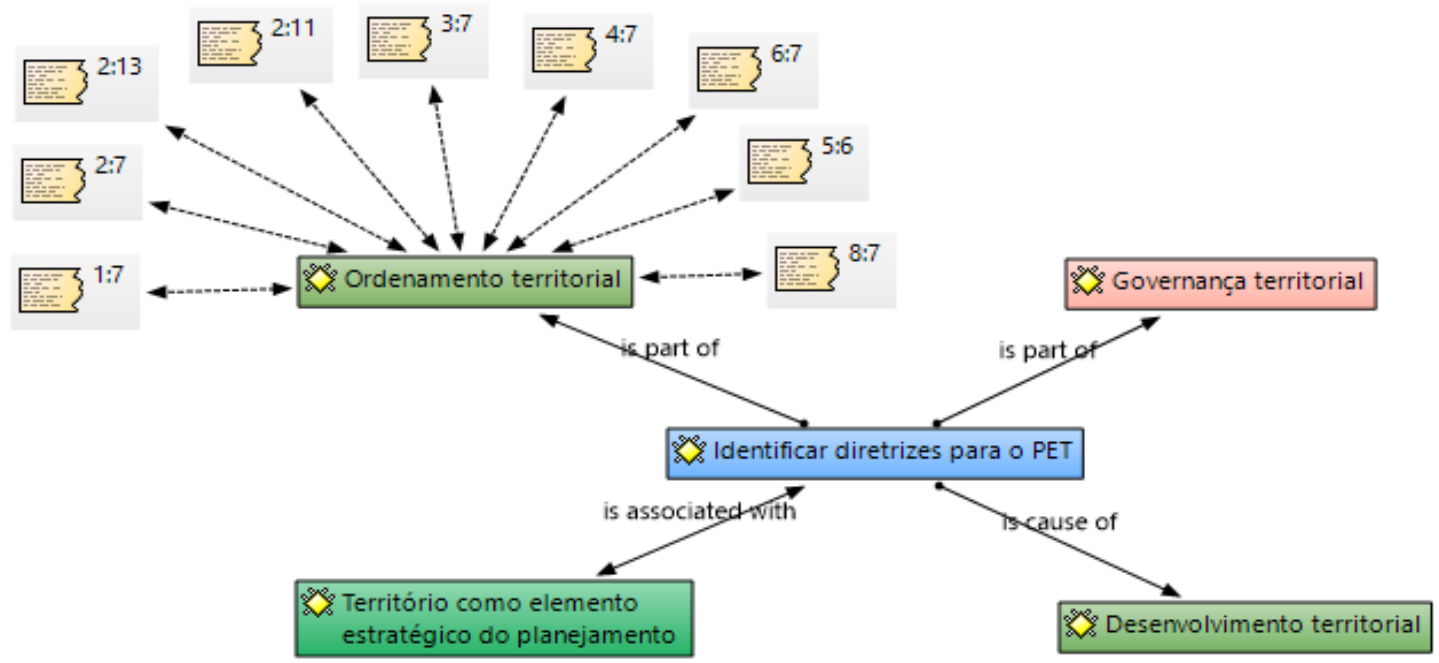

Figura 6 - Ordenamento territorial

Fonte: Elaborado pelos autores (2019)

De acordo com a figura, os entrevistados citaram comentários sobre o ordenamento territorial. Na revisão da literatura, percebeu-se que o ordenamento territorial foi dado pela da adoção de termos como descentralização, autonomias, participação e planejamento do território (Coraggio, 1994; Cirio, 2016). Nessa lógica o entrevistado E3, menciona que entende o ordenamento territorial como a autonomia de cada região de planejamento. De acordo com o entrevistado, o território do estado do Ceará, ele tem diferentes regiões com desafios comuns.

Nesse contexto, o ordenamento do território passa pela organização territorial (Cirio, 2016). Corroborando com esse apontamento, E2 menciona que o ordenamento territorial ele passa pela organização territorial. Proporcionando uma nova configuração da estrutura estadual, por meio de um desenho da configuração territorial, justamente para ter essa 
percepção de como aquele território funciona. Nesse sentido, esse argumento é observado na resposta de E7. De acordo com esse entrevistado, o ordenamento territorial é a divisão do território em regiões de planejamento. Onde essas divisões, no contexto do território cearense, contemplam as catorze regiões de regiões de planejamento do estado.

Por fim, corroborando com E7, Gomes (2018) cita que essa divisão e/ou uma nova figura administrativa que reconheça os diversos territórios como unidades administrativas autônomas, é possível torná-los instrumentos de ordenamento territorial e de planejamento estratégico.

\subsubsection{Governança territorial}

Nas análises das entrevistas, identificou-se vinte e cinco trechos que relacionam-se a essa diretriz. Conforme expõe-se na figura 7.

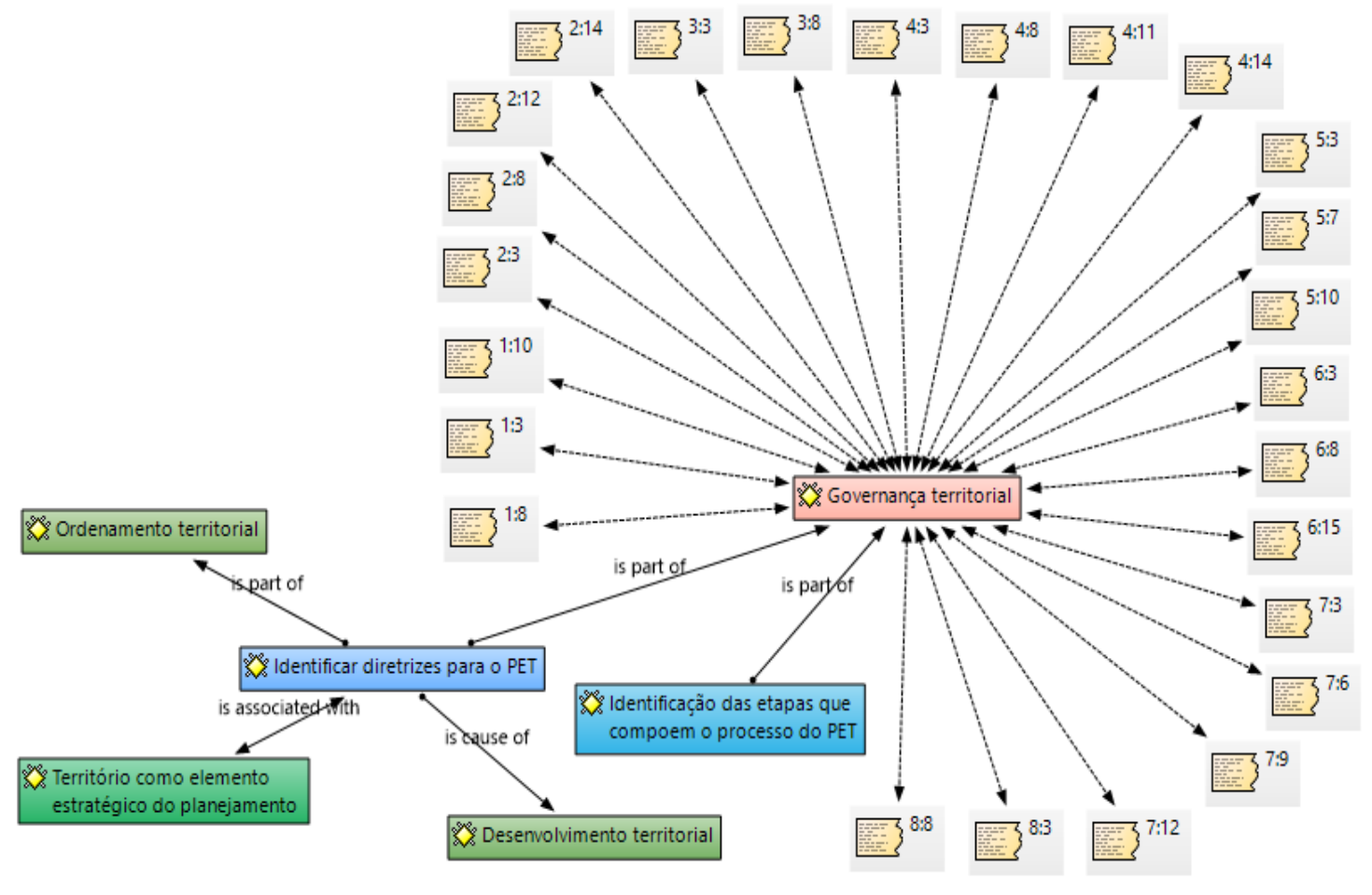

Figura 7 - Governança territorial

Fonte: Elaborado pelos autores (2019)

Diante da figura exposta e entre os relatos encontrados nas entrevistas, destaca-se que a governança territorial é uma responsabilidade compartilhada entre os indivíduos, ou as organizações públicas ou privadas, que têm interesses comuns (Dallabrida, 2011, 2013, 2016; Cançado et al., 2013; Ribeiro \& Toppan, 2015; Dallabrida et al., 2016; Abdala \& Nunes, 
2018). Esse apontamento é destacado por E7, "na governança territorial é essencialmente um processo participativo de todos os atores envolvidos no planejamento".

No entanto, a governança territorial, apesar dos propósitos inseridos em sua concepção teórica, enfrenta desafios na sua prática, originados pelo desacordo de muitas ações dos atores envolvidos no processo, tanto os públicos quanto da sociedade civil (Dallabrida et al., 2016). Esse argumento é abordado nas falas de E1 e E2: "o maior desafio é como eu vou estimular a participação popular, com o envolvimento dos municípios e das lideranças territoriais, nas discussões, nos debates, e na interlocução do que foi planejamento."

Desse modo, a governança é um elemento fundamental para o desenvolvimento dos territórios locais/regionais (Pires, et al., 2017). Nessa lógica, E3 destaca que "na estrutura de governança, é necessária que ela tenha a perspectiva regional”. Uma perspectiva regional, com a participação de toda a sociedade, por meio de núcleos de discussão e mobilização que se transformem depois numa célula de governança regional dentro do modelo de governança da Plataforma Ceará 2050, dentro da perspectiva do planejamento estratégico territorial (E3).

Entretanto, percebe-se que o entrevistado E7, discorda desse apontamento e prossegue, "não acho que a regionalização seja tão importante." O entrevistado continua, e cita "que o mais importante é definir regiões que sejam consistentes com todas as outras regionalizações das atividades governamentais e que supere os obstáculos institucionais." É preciso buscar novas soluções, modelos, recortes territoriais e pactos sociais (Gomes, 2018; Abdala \& Nunes, 2018).

Nesse ínterim, os entrevistados E4, E5 e E8, apontam soluções para superar esses obstáculos é por meio do convite da população. Ou seja, por meio de um planejamento elaborado, para garantir que os atores acompanhem as execuções a partir de cada território do Estado. Assim, conclui-se, que a governança territorial, busca a participação dos atores envolvidos no processo de planejamento. Desta forma, pode-se citar que uma boa governança territorial envolve a participação de todos os atores da sociedade. Proporcionando assim, o desenvolvimento territorial (Carmouze, 2019). 


\subsubsection{Desenvolvimento territorial}

Nas análises das entrevistas, identificou-se oito trechos que relacionam-se a essa diretriz. Conforme expõe-se na Figura 8.

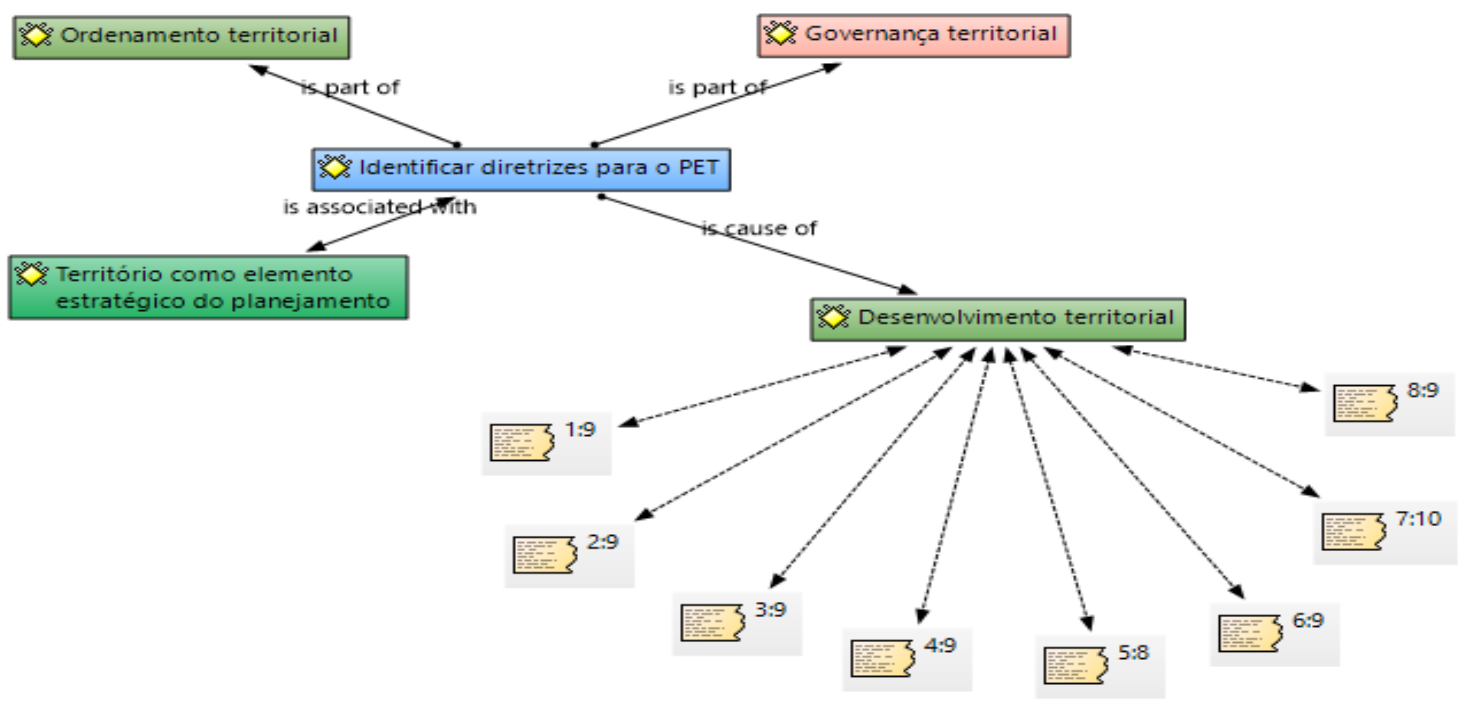

Figura 8 - Desenvolvimento territorial Fonte: Elaborado pelos autores (2019)

O desenvolvimento territorial é entendido como um processo de mudança continuada, situado histórica e territorialmente, mas integrado em dinâmicas intraterritoriais, supraterritoriais e globais, sustentado na potenciação dos recursos e ativos (materiais e imateriais, genéricos e específicos) existentes no local (Dallabrida, 2015, 2016). Assim, verificou-se também que o desenvolvimento territorial está relacionado com 0 ordenamento territorial. Pois, de acordo com E1 "o desenvolvimento territorial é fundamenta!" Esses instrumentos de ordenamento, eles vão servir como um instrumento auxiliar para as estratégias definidas no âmbito do Ceará 2050 e são fundamentais para alcançar o desenvolvimento territorial. Nessa perspectiva, para alcançar o desenvolvimento territorial, é necessária uma construção participativa, reconhecendo-se diferentes sujeitos, os distintos interesses, os anseios, os sonhos, as necessidades dos tempos e os territórios, as temporalidades, as territorialidades, a conquista de autonomia e as peculiaridades do território (Moraes \& Ribeiro, 2016). 
Corroborando com o exposto, E3 e E8 citam que "para atingir esse desenvolvimento, você tem que conquistar o engajamento de todos os atores envolvidos." Para os entrevistados o engajamento é matéria-prima fundamental, pois o engajamento vem da participação e a participação ela traz como subproduto, maior legitimidade e até mesmo maior conteúdo para o que foi planejado (E3). No entanto, as pesquisas que analisam a construção do desenvolvimento territorial, relacionam esse processo com a coerência e os acordos estáveis entre os diversos entes governamentais e os demais atores envolvidos (Pires, et al. 2017).

Nesse sentido, E7, comenta que "para alcançar o desenvolvimento territorial, é necessário que haja um entendimento entre os diversos entes governamentais e privados que atuam na região de planejamento." Nessa perspectiva, para alcançar o desenvolvimento territorial, o Estado e os demais atores envolvidos nesse processo de desenvolvimento, tateiam estratégias e novas formas para criar condições para o desenvolvimento territorial (Pires, et al. 2017).

Para complementar esse apontamento, E2, destaca que "o desenvolvimento territorial deve ser alcançado por meio do reconhecimento das diversas frentes que compõem o território (aspirações, estratégias e articulação entre atores locais)." Desta forma, o desenvolvimento territorial corresponde a um novo discurso acadêmico, ou paradigma científico, que considera múltiplas dimensões: social, cultural, econômica, política, ambiental e a dimensão territorial (Dallabrida, 2017; Guedes, 2018).

Nessa lógica, E4 complementa, que o desenvolvimento territorial deve levar em consideração todas essas dimensões, como uma parte do todo, cada território ele tem que ter as ações próprias que vão contribuir para com o resultado que o estado precisa obter para alcançar o desenvolvimento (E4). Assim, essas dimensões devem estar conectadas por meio da integração e operação do todo, de tal modo que, relacione os aspectos específicos de cada dimensão. De forma a alcançar uma sinergia positiva, proporcionando que o desenvolvimento seja funcional, dinâmico, global, cauteloso, flexível, não finalista, evolutivo e prospectivo (Aliseda \& Velarde, 2018a).

Nesse contexto, E5, destaca que para alcançar esse desenvolvimento, deve-se levar em consideração o que sedimenta o território. É preciso haver uma sinergia das dimensões que 
compõem o desenvolvimento territorial. E tem a ver também, inicialmente com políticas públicas que você pode tentar trabalhar a ideia de como alcançar o desenvolvimento territorial (E5). Em relação às partes interessadas envolvidas no processo de desenvolvimento territorial, deve-se partir da inclusão da dimensão territorial e da afirmação de que o ordenamento territorial não é apenas responsabilidade do governo local, mas sim um esforço compartilhado entre os atores-chave do território, independentemente de serem atores públicos, privados ou entidades sem fins lucrativos (Ruano, 2019).

Assim, E6 complementa que "a inclusão da dimensão territorial na Plataforma Ceará 2050, aparece como garantidor desse desenvolvimento territorial." De acordo com o entrevistado, é preciso pensar o ordenamento do território que contemple e envolva todos os atoreschaves. Agregando a participação de agentes dos governos, do setor produtivo, academia e com a participação de agentes da própria sociedade civil, ONGs etc (E6). Conclui-se, diante do exposto que pensar o território de forma estratégica, por meio por meio do ordenamento territorial é essencial, para alcançar uma boa governança e, consequentemente, o desenvolvimento territorial (Carmouze, 2019).

\section{CONSIDERAÇÕES FINAIS}

O objetivo geral desta pesquisa foi propor diretrizes para o aprimoramento do processo de Planejamento Estratégico Territorial, na Plataforma Ceará 2050. Inicialmente, realizou-se um vasto levantamento da literatura, a fim de identificar diretrizes para "PET". Assim, vislumbrou-se a oportunidade de estudar um projeto de planejamento estratégico de longo prazo, denominado "Plataforma Ceará 2050". Sendo assim, conclui-se que o processo do PET é composto por três etapas: a análise do território, planejamento territorial e governança territorial.

Observou-se que, para os entrevistados, o PET pode ser definido como uma visão estratégica, trazendo uma percepção de longo prazo. Como também pode ser entendido por um planejamento estratégico sobre o território. Nesse sentido, é possível notar que o PET, de um modo geral, é oriundo do planejamento estratégico institucional de empresas tradicionais. 
Por fim, analisar e propor diretrizes para o PET no projeto Ceará 2050, nesse contexto, propõe-se 4 premissas: 1) O território deve ser compreendido como elemento estratégico do planejamento, subsidiando a tomada de decisão; 2) O ordenamento territorial é essencial para o desenvolvimento e para o planejamento adequado, nos territórios impactados; 3) Estabelecer governança com plena participação social é imprescindível aos processos de planejamento e 4) Seguir as demais diretrizes proporciona ao desenvolvimento territorial.

Assim, o estudo traz algumas contribuições, como a revisão de literatura que contém as principais abordagens sobre o processo do PET, além de apresentar o Plano Ceará 2050, no âmbito acadêmico. Apresenta-se, também, dois tipos de análises que até então não tinham sido feitas na literatura. A primeira análise foi feita entre os planos estratégicos que serviram como subsídio para refletir sobre o Ceará 2050 e a realização de entrevistas com pessoas que participaram do Plano Ceará 2050. E, assim, foi possível fazer a relação entre essas entrevistas e os achados na literatura pesquisada.

Entretanto, a pesquisa apresenta como limitação, o fato de ter sido realizada com a coordenação e a equipe do governo, as quais coordenam e fiscalizam o Plano Ceará 2050 respectivamente. Dessa maneira, não foi possível constatar e confrontar as opiniões de outros consultores ou empresas que contribuíram com o plano. Outro fator limitante foi o número reduzido de entrevistados - (universo de oito pessoas). Outra limitação da pesquisa, refere-se ao fato da Plataforma Ceará 2050, ainda estar em processo de construção e os resultados podem se alterar ao longo das próximas etapas de implantação e execução.

Todavia, são apresentadas três sugestões para futuros estudos a partir das descobertas da pesquisa a seguir: mapear a percepção da população cearense a respeito do processo do PET no Plano Ceará 2050; um levantamento com as pessoas que trabalham atualmente no Ceará 2050 como forma de avaliar e acompanhar os resultados já obtidos desde a sua implementação. E, por fim, essa pesquisa poderia ser replicada nos demais territórios e cidades brasileiras.

\section{Referências Bibliográficas}

Abdala, B. \& Nunes, J. (2018). Participação social e governança territorial: os desafios e as contradições de novos espaços políticos a partir da análise do colegiado territorial do Vale do Paranã, Goiás. Geografares - 
Revista do Programa de Pós-Graduação em Geografia e do Departamento de Geografia da UFES, vol. 3, p. 254279. ISSN 2175-3709.

Alexander, E. R. (2016). There is no planning - only planning practices: Notes for spatial planning theories. Plan. Theory 15 (1), 91-103.

Alexander, E. R. (1997). A mile or a millimetre? Measuring the 'planning theorypractice gap. Environ. Plann. B Plann. Des. 24 (1), 3-6.

Aliseda, J. M., Velarde, J. G. \& Hildenbrand A. (2018). Gobernanza y planificación territorial en las áreas metropolitanas. Análisis comparado de las experiencias recientes en Alemania y de su interés para la práctica en España. Obs. Medioambient, v. 21, p. 345-348. doi:10.5209/OBMD.62665.

Aliseda, J. M., Velarde, J. G. \& Mora, C. (2018b). Urban Planning: Methodology for the preparation of a Strategic Plan. International Journal of Economics and Management Systems, V. 3, p. 345-348. ISSN: 23678925.

Allmendinger, P. (2002). Planning Theory. Palgrave, New York.

Azevedo, G. and Bardal, D. (2016). Resumo das discussões: Planejamento territorial e monitoramento do desenvolvimento. In: Grandes Obras na Amazônica: aprendizados e Diretrizes. São Paulo: FGV EAESP - Centro de Estdos em Sustentabilidade, p 1 - 7.

Babbie, E. R. (1998). The Practice of Social Research. 8a ed. Belmont: Wadsworth Publishing Company. Pp. 4 65. ISBN 0-534-50468-X.

Bardin, L. (2016). Análise de Conteúdo. 3a reimp. da 1a edição de 2016: tradução Luis Antero Beto, Augusto Pinheiro. São Paulo: Edições 70. ISBN 978-85-62938-04-7.

Becker, D. F. (1998). Os limites desafiadores do planejamento. In: REDES, v. 3, n. 2. Santa Cruz do Sul: EDUNISC, dez. p. 87-105.

Brasil. (2001). Estatuto da Cidade: guia para implantação pelos municípios e cidadãos: Lei no 10257/01 que estabelece as diretrizes gerais da política urbana - 2a ed. - Brasília: Câmara dos Deputados, Coordenação de Publicações. ISBN 978-85-736-5343-4.

Breheny, M. J. (1983). A practical view of planning theory. Environ. Plan. B: Plan. Des. 10, 101-115.

Cançado, A. C., TAVARES, B., \& Dallabrida, V. R. (2013). Gestão Social e Governança Territorial: interseções e especificidades teórico-práticas. Revista Brasileira de Gestão e Desenvolvimento Regional - G\&DR, v. 9, n. 3, p. 313-353. ISSN 1809-239X.

Carmouze, L., Hernandez, S. \& Serval, S. (2019). Through the Looking-Glass: What Does Strategic Planning Reveal in French Local Governments? Strategic Planning in Local Communities. Governance and Public Management. V. janeiro, p. 9 - 44. ISSN 978-3-030-03436-8.

Carrière, J.-P. (2004). L'aménagement du territoire en Europe : vers une approche policêntrica multiscalaire. Analyse à partir du cas de l'espace atlantique ", in GUESNIER B. Et JOYAL A., Le développement territorial regards croisés sur la diversification et les stratégies, éd. ADICUEER, Poitiers, p. 61-80.

Carrière, J. P., Bock E. (2004). The development of the French intermediate cities: which role in a polycentric perspective ? Colloque de la Regional Science Association: Europe at the margins: EU regional policy, peripherality and rurality, Angers, 15 et 16 avril 2004, 20 pages.

Castells, M. \& Borja, J. (1996). As Cidades como Atores Políticos. Novos Estudos, CEBRAP, n.45, São Paulo.

Ceará. (2017). Secretaria de Planejamento e Gestão do Ceará (Seplag). Termo de referência para contratação de instituição de notória especialidade para a elaboração do plano estratégico de desenvolvimento de longo prazo do estado do Ceará - Ceará 2050. [Acesso em 03 nov. 2017]. Disponível em: http://www.ceara2050.ce.gov.br/artigos-e-publicacoes/recentes.

Cellard, A. (2010). A análise documental. In: POUPART, Jean et al. A pesquisa qualitativa: enfoques epistemológicos e metodológicos. Petrópolis: Vozes. ISBN 978-85-326-3681-2.

Chizzotti, A. (2011). Pesquisa qualitativa em ciências humanas e sociais. 4. ed. Petrópolis: Vozes. ISBN 85.326.3390-0. 
Cirio, G. (2016). Territorio y lugar en las concepciones e instrumentos de planificación territorial municipal: El partido de Quilmes, Buenos Aires, Argentina, 2004-2014. Tesis de posgrado. Universidad Nacional de La Plata. Facultad de Humanidades y Ciencias de la Educación. En Memoria Académica.

Collis, J., \& Hussey, R. (2005). Pesquisa em administração: um guia prático para alunos de graduação e pósgraduação. Tradução Lucia Simonini. 2 ed. Porto Alegre: Bookman. ISBN: 853-63-042279-7.

Coraggio, J. L. (1994). Territorios en transición: crítica a la planificación regional en América Latina. Universidad Autónoma del Estado de México Instituto Literario. Toluca, México.

Costa Filho, A. (2010). Estado-nação e construção do futuro. Brasília: Cepal; Ipea.

Costa, H. (2004). Planejamento estratégico. Brasília: Ministério do Planejamento, Orçamento e Gestão.

Dallabrida, V. R. (2011). Governança territorial e desenvolvimento: as experiências de descentralização políticoadministrativa no Brasil como exemplos de institucionalização de novas escalas territoriais de governança. Anais... Code. [Acesso em 15 jan. 2018]. Disponível em: http://www.ipea.gov.br/code2011/chamada2011/pdf/area7/area7-artigo11.pdf

Dallabrida, V. R. (2015). Territory Planning and Management: The Theory Debate in Brazil and a Prospect of Practice According to Theoretical Contributions on Territorial Governance. G\&DR. v. 11, n. 4 (número especial), p. 51-77, dez/2015, Taubaté, SP, Brasil. ISSN 1809-239X

Dallabrida, V. R., Marchesan, J., Rossetto, A. M., \& Filippim, E. S. (2016). Governança nos territórios ou governança territorial: distância entre concepções teóricas e a prática. Revista Grifos, v. 25, n. 40, p. 43 - 66. ISSN: 2175-0157.

Dallabrida, V. R. (2017). Teorias do Desenvolvimento: aproximações teóricas que tentam explicar as possibilidades e desafios quanto ao desenvolvimento de lugares, regiões, territórios ou países. Curitiba: CRV, 238. ISBN: 978-85-4441743-0.

Dasí, J. F., Pastor, O. V. (2016). Planificación Territorial Fronética y Ética Práctica. Acortando las Distancias entre Plan y Poder (Política). Finisterra, LI, 101, pp. 45-69.

Davidoff, P. (1973). Advocacy and Pluralism in Planning. In: A. Faludi, ed. A Reader in Planning Theory. New York, NY: Pergamon Press, pp. 277-296.

Davidoff, P. \& Reiner, T. (1962). "A Choice Theory of Planning”. Journal of the American Institute of Planners, 28 (3) May, pp. 103-15.

El-Kholei, A. O. (2016). Developmentof Planning Theory and Implications on Planning Education and Practive Presentation. March. DOI: 10.13140/RG.2.1.4224.7440.

Escudero, C. S. (2014). Métodos y aplicaciones de la planificación regional y local en América Latina. CEPAL. Desarrollo Territorial. ISSN 1994-7364.

Faragó, L. (2004). The General Theory of Public (Spatial) Planning. The Social Technique for Creating the Future. Centre for Regional Studies of Hungarian Academy of Sciences. Discussion Papers, No. 43.

Friedmann, J. (1987). Planning in the Public Domain. New Jersey, Princeton University, Press.

Friedmann, J. (1966/67). Planning as a Vocation. - Plan Canada. 6. 99-124 pp., 7. 8-26. pp.

Giacobbo, M. (1997). O desafio da implementação do Planejamento Estratégico nas Organizações Públicas. Tribunal de Contas da União - TCU. Revista do TCU, n. 74, pp. 73-108.

Giovanella, L. (1991). As origens e as correntes atuais do enfoque estratégico em planejamento de saúde na América Latina. Cadernos de Saúde Pública, s.l., v. 7, n. 1, p. 26-44.

Gomes, B. (2018). Governança territorial e gestão integrada. Página 22, v. Jun. n. 108, p. 34, São Paulo - SP. ISSN: $1982-1670$.

Graziano, J. S. (2007). Carta d 5o Congresso Nacional do MST. Nova Agenda para a Reforma Agrária. 11 a 15 de jun. [Acesso em 15 jan. 2018]. Disponível em: https://reporterbrasil.org.br/2007/06/carta-do-5-congressonacional-do-mst/. 
Guedes, M. do S. B. (2018). Avaliação das Práticas de Governança: Estudo de Caso do Programa de Fomento a Atividades Produtivas Rurais no Território da Cidadania Alto Oeste Potiguar. Revista Científica Multidisciplinar Núcleo do Conhecimento. Ano 3, Ed. 2, Vol. 1, pp. 85-149. Fevereiro. ISSN: 2448-0959.

Gutiérrez, P. M. (2014). Planificación participativa: Crítica, métodos y experiencias. Construyendo Ciudadanía, 13. Observatorio Internacional de Ciudadanía y Medio Ambiente Sostenible - CIMAS. ISBN: 978-84-617-31787.

Habermas, J. E. (1984) The Theory of Communicative Action: Reason and the Rationalization of Society, Trans. by T. McCarthy. Boston: Beacon Press.

Hague, C. (1991). A Review of Planning Theory in Britain. The Town Planning Review, Vol. 62, No. 3, pp. 295310.

Harrison, P. (2014). Making planning theory real. Plan. Theory 13 (1), 65-81.

INNES, J. E. (1995) Planning theory's emerging paradigm: communicative action and interactive practice, Journal of Planning Education and Research, 14, pp. 183 - 189.

Krambeck, C. (2007). Planejamento Territorial Rural: Análise do Processo de Elaboração de Planos Diretores em Municípios Rurais, o Caso de Papanduva - Santa Catarina'. 186 f. Mestrado em Arquitetura e Urbanismo Instituição de Ensino: Universidade Federal de Santa Catarina, Florianópolis.

Maricato, E. (2001). Brasil, Cidades - Alternativas para a crise urbana. Petrópolis: Vozes. pp. 47-124.

Matus, C. (1984). Planificación, liberdad y conflito. In: ARGENTINA. Evaluación y uso de la información: manual de estrategias para el uso e incorporación de la información de evaluación. Buenos Aires. p. 198-225.

Mathis P. 2004. L'Observatoire en Réseau de l'Aménagement du Territoire Européen et les conséquences sur les territoires: l'exemple du thème 121 réseaux de transports», Territoires 2020, n 11, p. 75-92.

Meyerson, M. \& Banfield, E. C. (1955). Politics, Planning and the Public Interest. Glencoe. The Free Press.

Mintzberg, H. (1994). The rise and fall of strategic planning. Prentice Hall, Englewood Cliffs.

Mintzberg, H. (1990). Strategy Formation, Schools of Thought. - Fredrickson, J. W. (ed.) Perspectives on Strategic Management. New York, Harper Business. 105-235. pp.

Moraes, S. C., Ribeiro, M. da S. (2016). Governança para o desenvolvimento territorial: da concepção à ação o caso do programa Pará Rural. Geousp - Espaço e Tempo (Online), Vol. 20, n. 2, pp. 312-329. ISSN $2179-0892$.

Muller, J. (1992). From survey to strategy: Twentieth century developments in western planning method. Plann. Perspect. 7 (2), 125-155.

Nascimento, J. W. S. do, Barros Neto, J. de P. (2019). Desafios para o Processo de Planejamento Estratégico Territorial de Longo Prazo: o Caso do Plano Ceará 2050. In: VIII Encontro de Administração Pública da ANPAD (EnAPG), 2019, pp. 1-11. Fortaleza. Anais..., [Acesso em 04 nov. 2019]. http://www.anpad.org.br/sobre div academicas.php.

Nascimento, J. W. S. do. O processo de Planejamento Estratégico Territorial (PET): análise da Plataforma Ceará 2050. 109 f. Dissertação (mestrado) - Universidade Federal do Ceará, Faculdade de Economia, Administração, Atuária e Controladoria, Progrrama de Pós-Graduação em Administração e Controladoria, Fortaleza, 2019.

Pinto, D. G., Monzoni Neto, M. P. \& Ang, H. G. (2018). Grandes obras na Amazônia: aprendizados e diretrizes [recurso eletrônico] - 2.ed. - São Paulo: FGV-EAESP/FGVces, 302, URI: http://hdl.handle.net/10438/18320.

Pires, E. L. S., Fuini, L. L., Figueiredo Filho, W. B., Mendes, E. L. (2017). A governança territorial revisitada: dispositivos institucionais, noções intermediárias e níveis de regulação. GEOgraphia, Vol. 19, n. 41, pp. 24-38. ISSN 1517-7793 (eletrônico).

Pissourios, I. A., Lagopoulos, A. P. (2018). Defining the unitary types of urban uses: urban uses, land uses and land-use zones. Surv. Rev. 1 - 15.

Plataforma Ceará 2050. (2019). Portal do Governo do Estado do Ceará. Ceará 2050: Estado lança plataforma para debater desenvolvimento sustentável dos próximos 30 anos. [Acesso em 15 jan. 2019]. Disponível em: 
https://www.ceara.gov.br/2017/10/02/ceara-2050-estado-lanca-plataforma-para-debater-desenvolvimentodos-proximos-30-anos/.

Reade, E. (1987). The Theory of Town and Country Planning', in Healey, P., McDougall, G. and Thomas, M. (eds), op. cit., N33, pp. 43-58.

Reese, E. (1999). Planes estratégicos: limitaciones y oportunidades. Curso internacional. Ciudad Futura. Nuevas modalidades en planificación y gestión de ciudades. Mayo de 1999, Rosario. [Acesso em 02 jun. 2019]. http://vecinosvalladolid.org/IMG/pdf/Reese Eduardo-Planes Estrategicos limitaciones y oportunid.pdf.

Ribeiro, J. R., Toppan, R. N. (2015). Território e governança: as principais contribuições da geografia para pensar o desenvolvimento. Revista Brasileira Multidisciplinar, Vol. 18, n. 2, pp. 28-43. ISSN: 2527-2675.

Richardson, R. J. (2017). Pesquisa Social: métodos e técnicas. São Paulo: Atlas, 4a ed. ISBN: 8522-4211.

Rio Grande do Sul. (2016). Secretaria do Planejamento, Mobilidade e Desenvolvimento Regional. Plano Estratégico de Desenvolvimento Regional do COREDE Vale do Rio dos Sinos - CONSINOS 2016 - 2026. Porto Alegre - RS. ISSN: 3507-1281.

Rivera, U. (1992). Planejamento e programação em saúde: um enfoque estratégico. São Paulo: Cortez.

Ruano, J. M. (2019). Actors, Aims and Challenges of Local Strategic Planning in Spain. In: Hințea C., Profiroiu M., Țiclău T. (eds) Strategic Planning in Local Communities. Governance and Public Management. Palgrave Macmillan, Cham. Governance and Public Management. Vol. 30 January, pp. 157-177. ISBN 978-3-030-034368.

Silva, E. R.. (2012). O Planejamento Estratégico sem plano: uma análise do empreendedorismo urbano no Brasil. Revista de Geografia e Ordenamento do Território, n.o 2 (Dezembro). Centro de Estudos de Geografia e Ordenamento do Território. Pág. 279 a 306.

Silveira, R. B., Léo H. \& Sonaly, R. (2013). Identificando correntes teóricas de planejamento: uma avaliação do Plano Nacional de Saneamento Básico (Plansab) - Rev. Adm. Pública - Rio de Janeiro 47(3):601-622, maio/jun.

Silveira, R. L. L., \& Pereira, M. (2018). Políticas recentes de ordenamento territorial e planejamento regional em Portugal e no Brasil: características, semelhanças e particularidades. Revista Brasileira de Gestão e Desenvolvimento Regional - G\&DR, Vol. 14, n. 5, pp. 220-236. ISSN 1809-239X.

Sorkin, D. L., Ferris, N., \& Hudak, J. (1984). Strategies for cities and counties: a strategic planning guide. Washington, DC : Public Technology, Inc.

Stiftel, B. (1995). Symposium: teaching planning theory - introduction, Journal of Planning Education and Research, 14, pp. 155 - 156.

Stiftel, B. (2000). Planning theory. The National AICP Exam preparation course guidebook. Washington, DC: American Institute of Certified Planners. p. 4-16.

Taylor, N. (1998). Urban Planning Theory Since 1945. Sage, London. Lagopoulos, Alexandros Ph, 2018a. Landuse planning methodology and middle-ground planning theories. Urban Sci. 2 (3), 93.

Teitz, M. B. (1996). American Planning in the 1990s: Evolution, Debate and Challenge. Urban Studies, Vol. 33, № 4 - 5, pp. 649 - 671.

Viana, D. (2018). Necessário, mas não suficiente. Projetos de infraestrutura na Amazônia deixam aprendizados: o licenciamento ambiental não basta, é preciso haver também um planejamento territorial integrado. REPORTAGEM GRANDES EMPREENDIMENTOS, Página 22. Vol. junho. pp. 26 - 29. ISSN: 1982-1670.

Viktorovna, B. I. (2014). Extrapolational look at the current state of Territorial Strategic Planning in Russia. Science Journal of Volgograd State University. Vol. 6, n. 7, pp. 96 - 102. ISSN 1998-992X.

Watson, V. (2008). Down to earth: linking planning theory and practice in the' metropole' and beyond. Int. Plan. Stud. 13 (3), 223-237.

Yin, R. K. (2010). Estudo de caso: planejamento e métodos. 4. ed. Porto Alegre: Bookman. ISBN: 85-7307-852-9.

Zhikharevich, B. S., \& Pribyshin, T. (2014). Diffusion of practic of strategic planning in Russian cities and towns in 1997-2013. Regional Research of Russia, Vol. 4, n.4, pp. 279-285. ISSN 20799705. 